\title{
Development of Power System for a Small Size Solar Car
}

\author{
Ayalew Mesfin Mitiku', Shao Yi-Ming ${ }^{2}$ \\ ${ }^{1}$ Chongqing Jiaotong University \\ No.66, XueFu Ave., Chongqing, China \\ 611150110003@mails.cqjtu.edu.cn; sym@cqjtu.edu.cn \\ ${ }^{2}$ Chongqing Jiaotong University \\ No.66, XueFu Ave., Chongqing, China
}

\begin{abstract}
In the world of today, Automotive industries are facing two main challenges; finding the ways to maximize profit on one side and meet environmental compatibility in the other. One of the methods used to resolve these key issues is by developing a solar car which maintains a great deal of efficiency. To develop a power system for a small size solar car; identifying components and specifications, component matching for the particular power requirement were done. In addition, using assembly language the program was written then executing and simulating using Keil $\mu$ vsion3 and professional7 Proteus software respectively to demonstrate the functionality of the power system of the solar car. The result showed that identifying either the day time or night time, then displayed the following information on Liquid Cristal Display (LCD): charging, full battery, motor On, low battery motor Off and the amount of voltage of the battery.
\end{abstract}

Keywords: Photo Voltaic panel, charge controller, battery, microcontroller, solar car

\section{Introduction}

Now a day in the Automotive industry, energy is one of the most concerns, especially fuel energy consumption of a vehicle is very important parameter in worldwide. Due to some factors the world changing the face towards renewable energy, rather than petroleum fuel energies, these include wind, geothermal, ocean, tidal and solar energy.

Solar energy is currently a vital in the world for automotive vehicles. The reason behind are [8]:

- Solar energy is a completely renewable resource. This means that even when we cannot make use of the sun's power because of night time or cloudy and stormy days, we can always rely on the sun showing up the very next day as a constant and consistent power source.

- Solar cells make absolutely no noise at all. They do not make a single peep while extracts useful energy from the sun.

- Solar energy creates absolutely no pollution. This is perhaps the most important advantage that makes solar energy so much more practical than oil. Oil burning releases harmful greenhouse gases, carcinogens and carbon dioxide into our precious air.

- Very little maintenance is required to keep the solar cells running. There are no moving parts in a solar cell, which makes it impossible to really hurt them. Solar cells tend to last a good long time with only an annual cleaning to worry about.

- Solar energy does not emit air and water pollutants.

- Solar energy does not produce greenhouse gases, which are linked to global warming and climate change.

- It has no cost.

- Does not require energy suppliers to be imported from other places.

Solar-powered cars are powered by sunlight that is converted to electricity by the photovoltaic cells that line the car's exterior. This is done through the exchange of protons and electrons inside of the solar cell. The main components of a solar car are its solar array, which collect the energy from the sun and converts into usable energy. The solar cell collects a portion of the sun's energy and stores it into the batteries of the solar car. Before charging the battery, solar battery charge controller converts the energy collected from the solar array to the proper system voltage, so that the batteries and the 
motor can use it. After the energy is stored in the batteries, it is available for use by the motor and motor controller to drive the car.[9]

\section{Methods}

\subsection{Sizing and Selection of the Components of Power System of Solar Car}

The power system of solar operated car requires the following main components; solar panel, battery and charge controller. As shown in fig. 1. The overall power system looks like as follow:

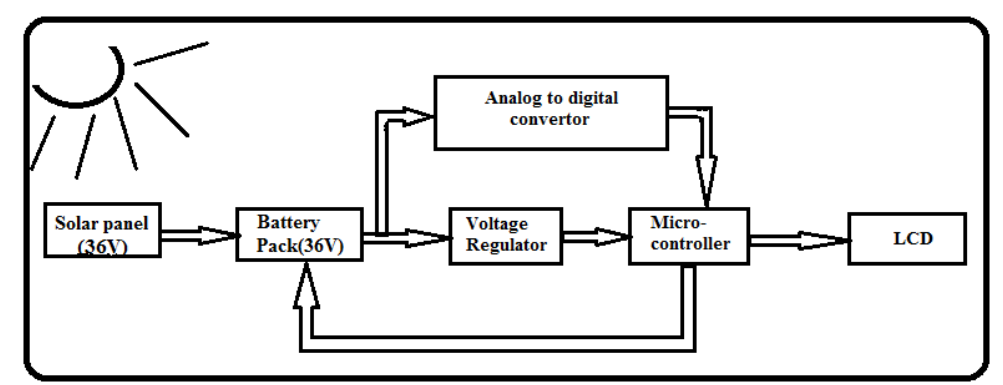

Fig. 1: Block diagram of solar car power system.

To determine the roof of solar panel area, the efficiency of a panel is important in order to choose the correct panels for the photovoltaic system. For smaller roofs, more efficient panels are necessary, due to space constraints. Now, solar panels are available having the efficiency up to $20 \%$ [6][7]. The motor requires $1124 \mathrm{~W}$, so the solar panel is required to produce $1500 \mathrm{~W}$ at $36 \mathrm{~V}$ because of for additional accessory uses. The total area of the solar panel governed by the following equation:

$$
\eta_{\max }=\frac{P_{\max }}{P_{i n}}=\frac{P_{\max }}{E_{\mathrm{gw}} \times A_{c}}
$$

Where: $\eta_{\max }$ is maximum efficiency, $\mathrm{P}_{\max }$ is total maximum power output, $\mathrm{P}_{\mathrm{in}}$ is power input, $\mathrm{E}_{\mathrm{SW}}$ is incident radiation flux, $\mathrm{A}_{\mathrm{c}}$ is an area of collector (solar panel)

To determine the number of modules required for the required power output, first a single module power output must determine; let a $200 \mathrm{~W}$ output module is selected. Then the total maximum output power of the solar panel is the product of the number of modules and the power output of the module.

The modules are connected in parallel besides expected to be used for 8hours in a day to recharge the battery. So power available from the solar panel in a day is calculated as:

$$
\text { Energy output/Day }=\text { Pmax } \times \text { Number of hr used per day }
$$

Therefore the selected solar panel[2] [3] and battery[5] parameters with specification are listed in table 1 and table 2 respectively.

Table 1: specifications of solar panel.

\begin{tabular}{|l|c|}
\hline \multicolumn{1}{|c|}{ Parameters } & Specifications \\
\hline Type of solar panel & Mono-crystalline \\
\hline Number of modules & 8 \\
\hline Total maximum power output & $1500 \mathrm{~W}$ \\
\hline Voltage output & $36 \mathrm{~V}$ \\
\hline Maximum current output & $44.48 \mathrm{~A}$ \\
\hline Total Area of solar panel & $7.5 \mathrm{~m} 2$ \\
\hline Maximum efficiency & $20 \%$ \\
\hline Energy output per day & $12000 \mathrm{Whr} /$ day \\
\hline
\end{tabular}


Table 2: specification of battery.

\begin{tabular}{|l|l|}
\hline \multicolumn{1}{|c|}{ Parameters } & Battery size/specification \\
\hline Battery type & Sealed or Lead acid \\
\hline System voltage & $36 \mathrm{~V}(3$ batteries $)$ \\
\hline Battery capacity & $83.4 \mathrm{Ahr}$ \\
\hline Maximum system current & $41.7 \mathrm{~A}$ \\
\hline Expected recharge time & $8 \mathrm{Hrs}$ (from 3AM-11PM) \\
\hline Total hours of use & 2Hrs \\
\hline Battery power & $1.5012 \mathrm{KWatt}$ \\
\hline
\end{tabular}

Once connected a solar panel continuously charge the battery as long as solar irradiation is available. If it is not controlled; the batteries may get damaged due to overcharging. To prevent this, charge controllers are commonly put in between the solar panel's output leads and the storage batteries.

The developed solar battery charge controller is Pulse Width Modulation (PMW) type with 36V of voltage rating, 41.7A of maximum current rating and 1500W of Power received from solar panel.[1] [4]

\section{Results}

The developed PWM type solar charger controller circuit diagram has three functions with five features.

The three functions are

- Solar panel control mechanism.

- Battery charge control mechanism and

- Motor control mechanism.

The five features which will be displayed on the liquid crystal display (LCD) are:

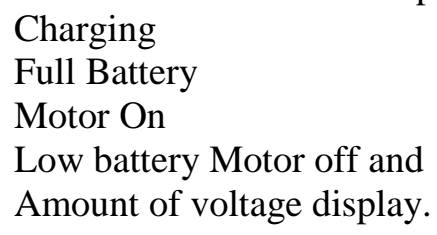

\subsection{Functions of Developed Circuit with Their Operation}

During daytime, the motor is connected to the battery and the battery is recharged with current from the solar panel. The microcontroller needs to know the presence of the solar panel voltage to decide the motor is to be connected or disconnected from the battery, or whether the battery should be in charge mode or fully charged mode. In fig. 2 a simple sensor potential divider is built based on resistors R11 and R12, and Zener diode ZD1, and transistor T3 for the presence of solar panel voltage.

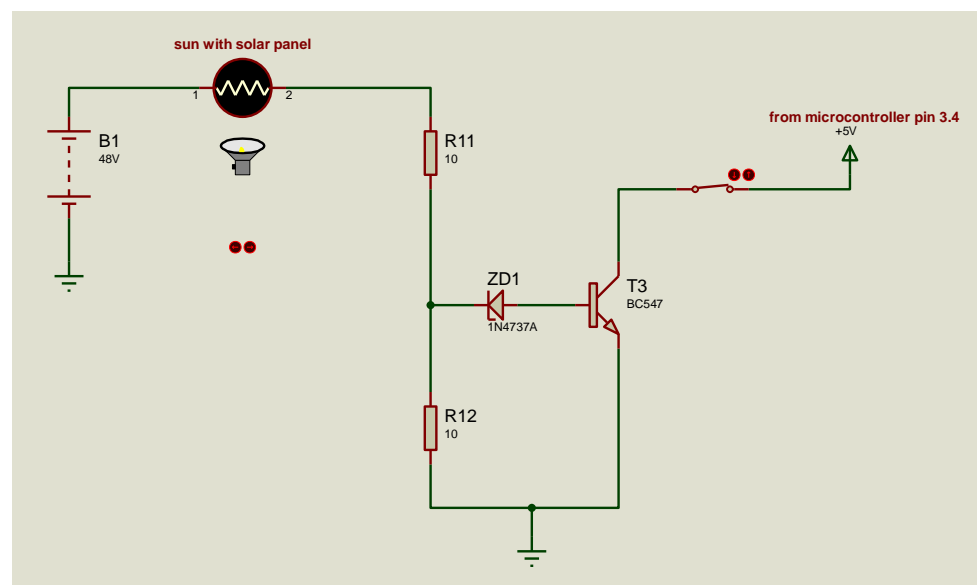

Fig. 2: Simple Solar panel control circuit operation 
The microcontroller P3.4 always got high voltage output. When the sun raises a certain amount of voltage can be generated by solar panel. If this voltage is enough for Zener diode ZD1 to be functional in reverse direction, the base of transistor T3 activates and P3.4 output voltage to be ground. Then the microcontroller understands that it is a day time.

When the sun sets (at night), the solar panel cannot generate any voltage this means the base of transistor T3 does not allow P 3.4 output voltage to be grounded. Then the microcontroller understands that it is a night time. Therefore this circuit is used to prevent the battery from discharged.

In fig.3. Relay RL1 connect the solar panel to the battery through diode D1. Under normal condition it allows the charging current from the panel to flow into the battery.

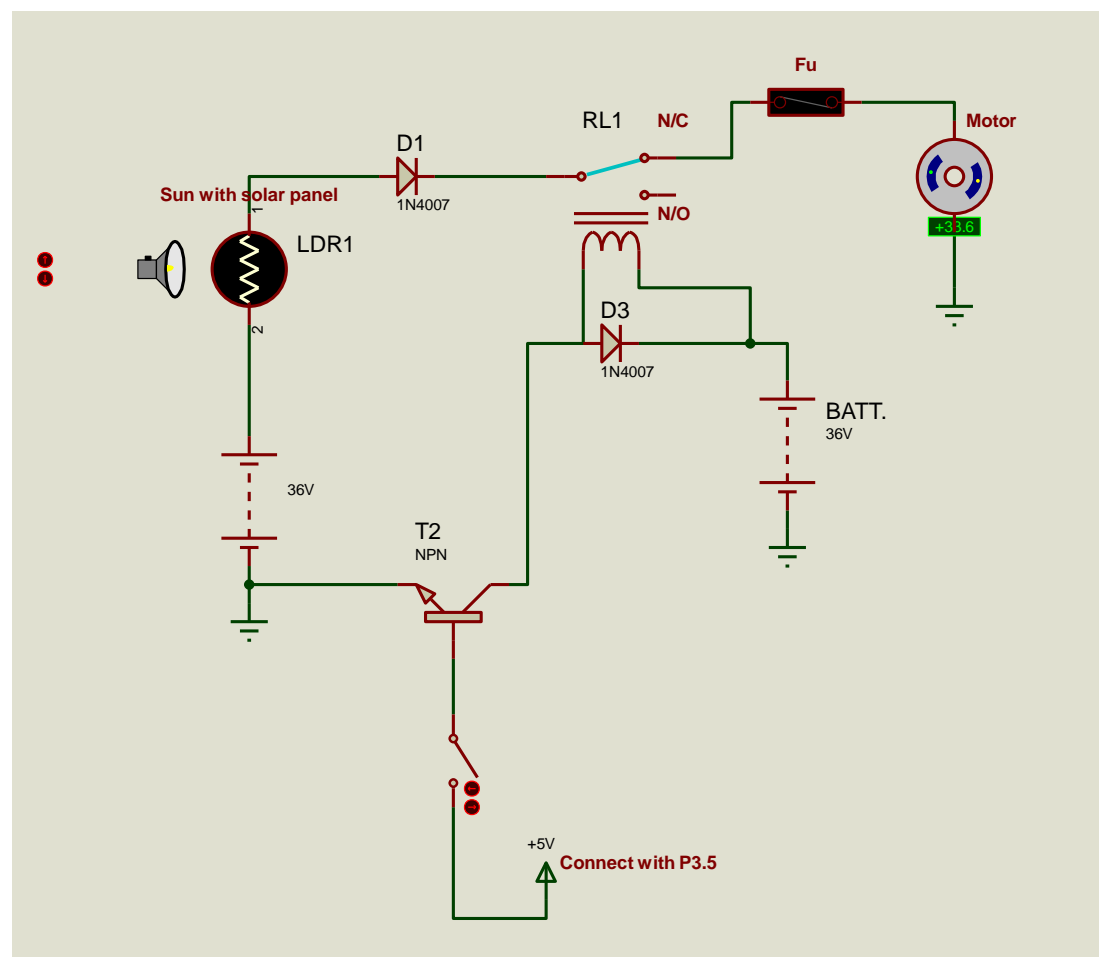

Fig. 3: Simple Battery charge control circuit operation.

When the battery is at full charge state, the charging current becomes pulsed. To keep the battery from over charging microcontroller P3.5 voltage becomes high, this is allowing the base of transistor T2 becomes active, the relay RL1 coil energized and the contact moves to normally-opened (N/O) position.

After 5minutes timer, the microcontroller P3.5 voltage becomes low and the base of transistor T2 gets deactivated. Then the relay contact returns to normally-closed (N/C) position due to the de-energized relay coil.

As shown in fig.4 one terminal of the motor is connected to the battery through the fuse and another terminal is connected with transistor T1. Optocoupler component is a tandem of light emitting diode (LED) and phototransistor. When LED gets voltage the phototransistor also activates.

If switch SW1 is On, the anode (A) of LED gets voltage the cathode $(\mathrm{K})$ terminal can ground in the microcontroller using P3.7. Therefore the microcontroller controls the K sides of the Optocoupler. 


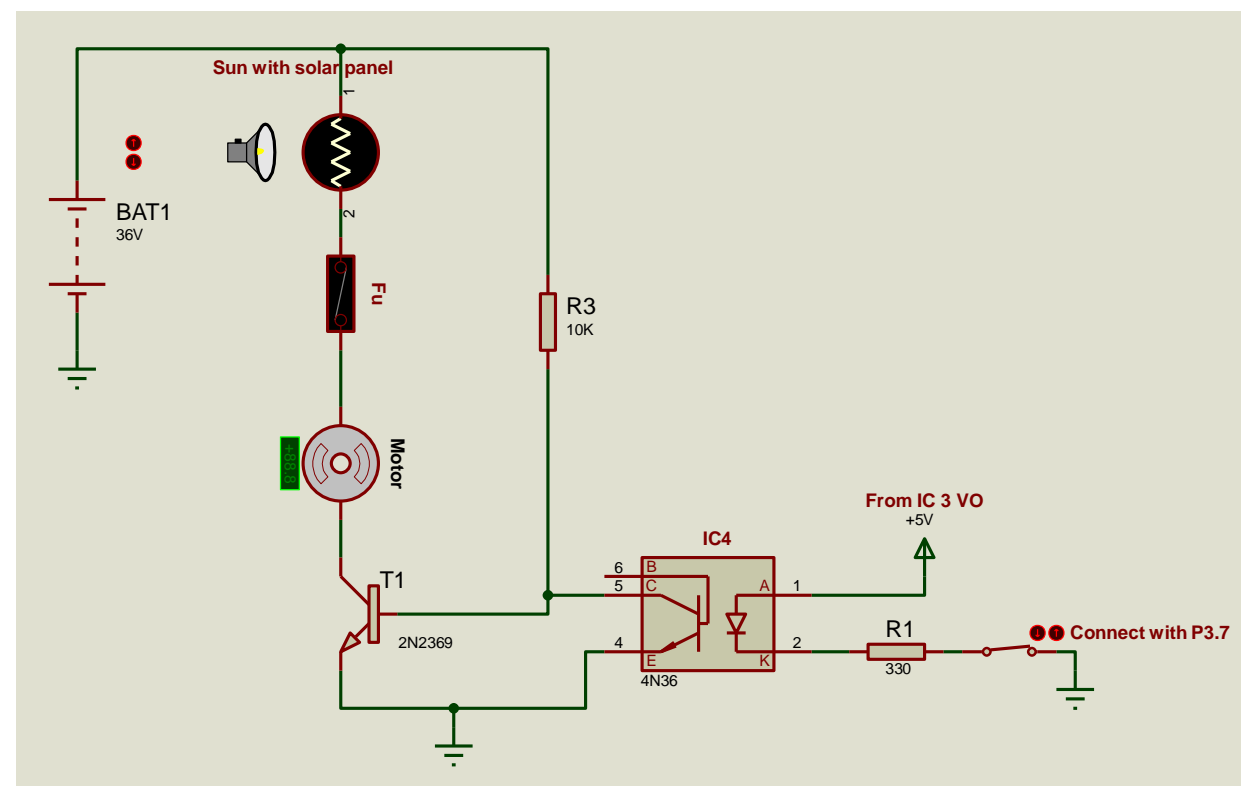

Fig. 4: Simple Motor control mechanism circuit operation.

When K terminal of LED gets low voltage from microcontroller P3.7, the base of transistor T1 is not active, the base of the phototransistor becomes active and allow the current passes from collector $\mathrm{C}$ to emitter $\mathrm{E}$ of the phototransistor. This means the motor is in Off condition.

When K terminal of LED gets high voltage from microcontroller P3.7, A and K terminal of current cancel each other and the base of the phototransistor becomes deactivate, then the base of transistor T1 becomes active this allows the motor can run by grounding through the collector to emitter of $\mathrm{T} 1$.

It is used to determine the situation either day or night to allow the running of motor or not respectively.

\subsection{Simulation}

The power system of the solar car includes the solar panel, solar battery charge controller and battery itself as shown below in the PWM type solar battery charge circuit simulation. The major components which are used are Voltage regulator, 16×2 LCD display, Microcontroller, and Analog- to- Digital Convertor to make this circuit functional.

During night time the solar panel does not work. So the motor must come to the Off position. Because if the motor runs, the battery gets discharged which makes it difficult to start and run the motor in the next morning. Therefore, for to avoid battery discharge the motor must be put off at night time. So when SW1 is ON only the voltage of the battery will be displayed on LCD screen. 


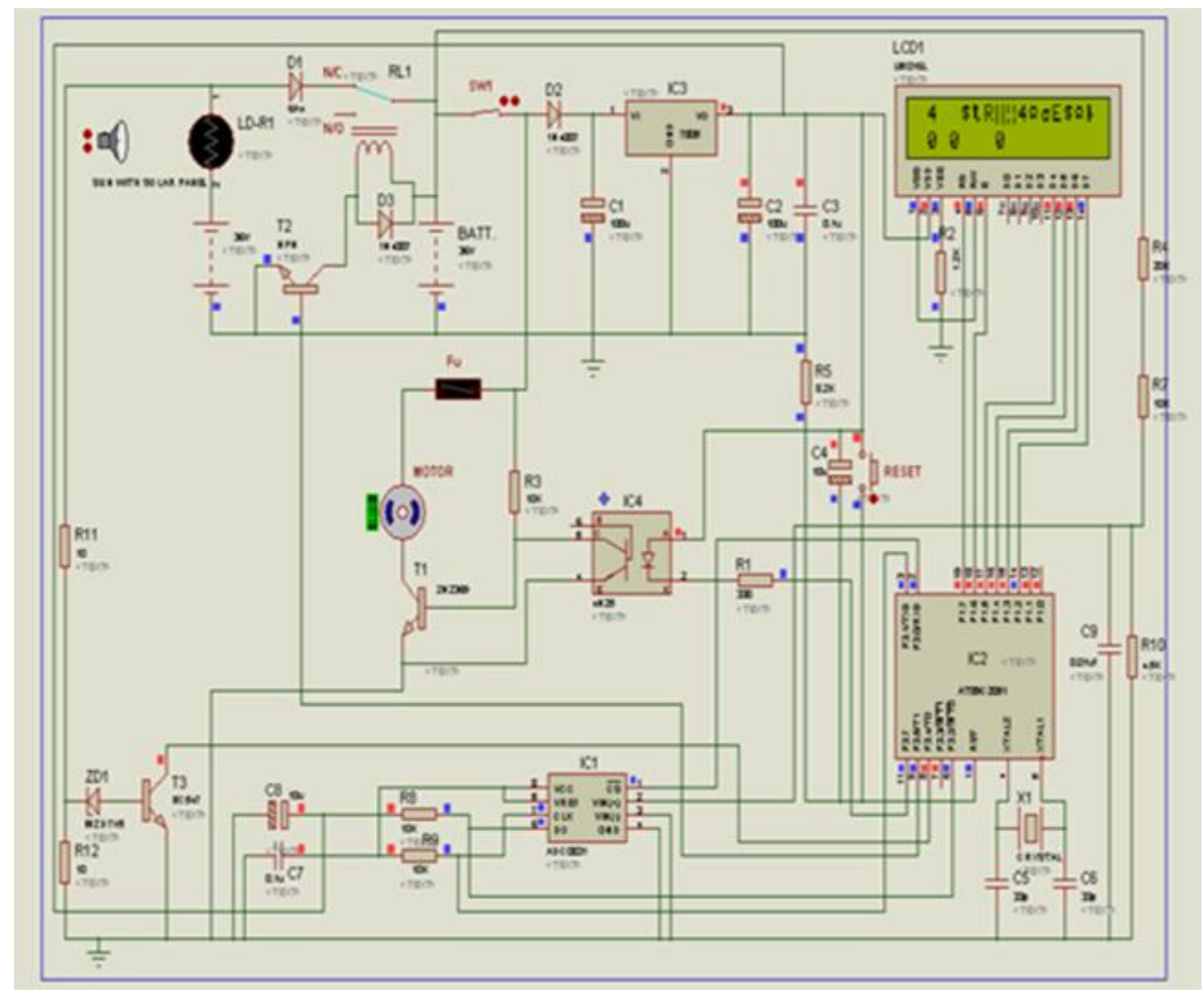

Fig. 5: Simulation of solar battery charge controller at night.

From the beginning of sunrise, a panel starts its function. This allows the solar panel control mechanism to become functional during the whole day time, then the microcontroller understands that it is a day time and then depending on the condition of the battery voltage the motor control mechanism starts working.

At the time of charging of the battery, if the battery voltage is sufficient to drive the motor, the motor control mechanism of the solar charger allows the motor to run, then "MOTOR ON" and "CHARGING" with the amount of volts message will be displayed on the LCD screen, but when the battery is low "LOW BATTERY, MOTOR OFF" message will be displayed. 


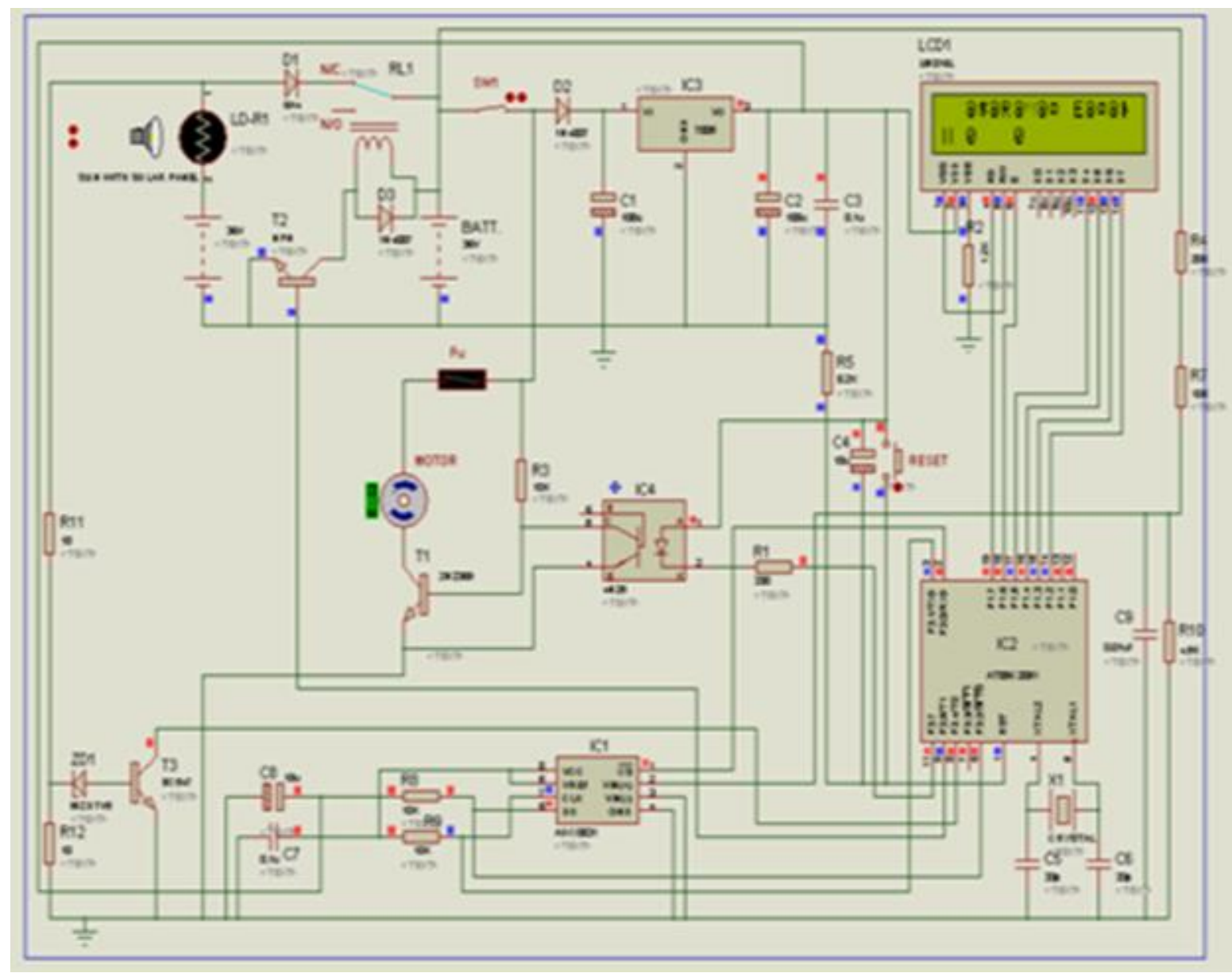

Fig. 6: Simulation of solar battery charging controller at day time during charging.

At a time of full charging, the charging current become pulsed, the relay contact moves to the N/O direction to keep the battery from overcharged and displayed "BATTERY FULL" message on the LCD screen so at the same time the 5 minute timer starts counting 5 minutes. After 5 minutes the relay contact returned to the N/C position to recharge the battery.

\section{Conclusion}

This study develops the power system for a small size of the solar car. Appropriate components required for power system were selected. 8 modules of mono-crystalline solar panels with a 200 watt and $36 \mathrm{~V}$ output were selected to give overall solar panel power output of 1500Watts.

The battery pack is consisting of 3 batteries, each of $12 \mathrm{~V}$ capacity giving 36 volts in total. The battery takes $8 \mathrm{hrs}$ to get fully charged and operates for the duration of $2 \mathrm{hrs}$.

The circuit of 36V PWM type solar battery charge controller and power system of a small size solar car was simulated by writing the program using assembly language and converted by Keil uvision3 to operate "charging" function of a solar battery charge controller. At last the simulation features of the PMW type of solar charge controller circuit is done on Proteus software.

The circuit allows running of the motor only during day time to secure battery voltage for starting and running the car for the next morning until the battery charging process starts.

\section{Acknowledgements}

This paper is funded by Chongqing Jiaotong University, College of Traffic and Transportation. 


\section{References}

[1] EPRI-DOE Handbook of Energy Storage for Transmission \&Distribution Applications, EPRI, Palo Alto, CA, and the U.S. Department of Energy, Washington, DC: 2003, 1001834.

[2] G. Davis, California energy commission, buying a photovoltaic solar electric system: a consumer guide, reprinted. 2000.

[3] M. C. Baechler, T. Gilbride, K. Ruiz, H. Steward, Building America Best Practices Series, Solar Thermal \& Photovoltaic Systems, vol. 6, 2007.

[4] M. A. El-Sharkawi, Fundamentals of electric drives. Brooks/Cole publishing company, California, 2000.

[5] S. Dhameja, Electric vehicle battery systems. Newnes press, USA, 2002.

[6] M. H. Westbrook, The electric car: development and future of battery, hybrid and fuel cell. United Kingdom, 2005.

[7] "Volume 3: The World PV Market to 2010," Photovoltaics in 2010, Luxembourge: office for official publications of the european communities, 1996.

[8] Solar power-advantages and disadvantages, [Online]. Available: http://www.alternate-power.org/solar-poweradvantages-and-disadvantages/

[9] W. Shih, How to builda solar car, 1998, [Online]. Available: http://www.solarcarchallenge.org/info/intro.html 